\title{
OPEN
}

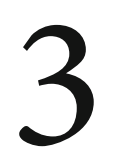

\section{Adopting TA in Central and Eastern Europe - An Organizational Perspective}

\section{Lenka Hebáková, Edgaras Leichteris, Katalin Fodor and Ventseslav Kozarev}

\begin{abstract}
Hebáková et al. provide from an insiders' perspective the process of adopting and adapting technology assessment to the practices of an already existing institutions. The strategic thinking of four very different organizations in four Central and Eastern European countries is candidly described and contrasted. The authors challenge the notion of technology assessment as a set of ideas and practices to be adopted en bloc. Rather, TA provides a package of inspiration that may help organizations to broaden their missions within the field of national science, technology and innovation policy to include, for instance, parliamentary policy support, facilitation of stakeholder dialogues or citizens' participation.

Klüver, Lars, Rasmus Øjvind Nielsen, and Marie Louise Jørgensen, eds. Policy-Oriented Technology Assessment Across Europe: Expanding Capacities. Basingstoke: Palgrave Macmillan, 2016. DOI: 10.1057/9781137561725.0012.
\end{abstract}


International communication among circles of professionals in policy and administration has always been a core impulse for the development of new institutional forms. But an equally universal prerequisite for the adoption of such new forms is the successful adaption of these forms to the national context. In this process of adaption and translation, entrepreneurs within existing institutions play a crucial role. It is their commitment and energy that propel institutional reforms, and it is their creative negotiation of the 'space of opportunity' which helps to shape nationally acceptable solutions for adoption of new institutional forms.

In this chapter, we zoom in on the process of attempting to adapt TA to the institutional realities of the Central and Eastern European partner countries. We recount this process such as it was experienced by the PACITA partner organizations from those countries.

\section{The inside scoop: taking TA on board in existing organizations}

For the Technology Centre of the Academy of Sciences of the Czech Republic (hereafter, 'the Centre'), established 1994 as part of early reforms in the post-soviet era, taking part in PACITA has created a lot of internal interest and debate concerning the concepts and practices of TA. But far from being seen as any revolutionary change, TA is seen to fit naturally alongside already existing organizational priorities. To explain this fit, it is useful to understand the role of the Centre. The Centre is a key organizational player in the development of the Czech STI governance system that provides analytical support for several governmental actors in that field. The Centre often acts as an intermediator among different government bodies involved in STI policy formation, and it serves as a connector to international STI collaboration, serving for instance as the National Contact Points Centre for European Framework programmes for research and providing support to analyses of international innovation systems conducted by EU institutions, UNIDO, OECD and so on. In terms of practices, the Strategic Studies Department, which was directly involved in PACITA, has long provided key services, such as policy analysis and evaluation, bibliometrics and foresight studies. It was the Centre's experience with foresight and its international networks with practitioners from other countries which provided the basis for 
the Centre's entrance into the PACITA partnership. And it is alongside this base of experience that the concepts and practices of TA are now becoming part of the organizational priorities of the Centre. From the point of view of the Centre, TA and foresight methodology are seen as part of a continuum of similar activities where the contribution of the TA tradition is its stressing the societal dimension of foresight, the value of participation and the idea of including parliament more directly in the policy process concerning STI issues. The various PACITA activities, including the example projects (described in part II of this book), have provided a welcome opportunity to seek out contacts with parliamentarians. Parliamentary debates concerning TA that were facilitated by the Centre have started a longer-term discussion about possible ways of including TA in the EU Operational Programmes funding research, development and education, as well as the possible role of the Centre as a support function for parliament. But again, this should be seen as a natural expansion of the already crosscutting institutional role of the Centre in the national STI policy system.

In Hungary, the participating Hungarian Academy of Sciences (HAS) has an institutional history that predates the former communist system by a hundred years. As such, it is viewed by the majority of stakeholders in the STI field as well as by the citizens as the most highly trusted public institution. This means that adopting TA takes place on a basis of an already well-established institutional platform and a highly vibrant range of international connections. Because the Academy is already a research-performing organization of significant size, which already has scientific policy advice role on the national level and international cooperation as a core part of its mission, TA is seen perhaps more as an addition to its internal palette of activities and competences than as any significant change in its role vis-à-vis other societal and governmental stakeholders. The Academy's culture is one of strong traditions and a high regard for the role of the scientific expert. The most salient feature of TA for the Academy has therefore been the overall idea of increasing the transparency of STI decision making and offering a platform for dialogue on socially relevant STI-related issues. Participating in PACITA has occasioned reflections on the usefulness of opening up to societal stakeholders in order to increase the societal responsibility of STI policies. Taking up relations with parliamentary representatives proved to be a fruitless effort during the PACITA project. It was partially due to the engagement of the potential partners in the period of the parliamentary 
elections in 2014. Here, the organization experienced that debating the concept of TA in broader terms was not as useful as were the example projects, which illustrated much more clearly the value of doing TA. Because the Academy is connected with the capacity-building effect of doing TA events, it will prioritize the creation of further concrete projects to serve as examples and to strengthen the human resource build-up internally in the organization. Such concrete projects, moreover, also serve to build networks of people interested in the specific policy issue being treated. This TA networking function is a key add-on for a few Hungarian institutions and, as such, is a valued outcome of the project for the Academy.

In Lithuania, in contrast to the well-established Czech and Hungarian partner organizations, the Knowledge Economy Forum is a relatively newer organization. The Forum plays an ever-changing role of pushing the development of the national STI institutions, a role which was first defined at the Forum's establishment a little more than a decade ago in terms of promoting business interests. With increasing funding going to early-stage $R \& D$ in support of innovation, this early mission was in some sense accomplished, and new steps towards further advancement of the national innovation system had to be found. In this situation, the opportunity presented by PACITA of considering in depth the role that TA may play in the institutional development of the country was well timed. Compared to the 'first wave' of TA institutionalization in Western Europe, the Forum's origins as an interest organization might have been thought to preclude adoption of the traditional role of a TA organization, where 'neutrality' has been seen as a central virtue. But from a reformist perspective, it makes sense in the Lithuanian context to promote greater institutional and political attention around societal issues related to STI. Authors on national systems of innovation have long stressed the need to build trust through cross-institutional dialogue. And social and environmental issues become increasingly important dimensions of international product competition. The Forum has thus come to see it role as promoting in a more complex manner the interests of its constituents through the development of dialogical forms of policy formation that take into account environmental and social issues related to the innovation-driven economy. In promoting this new focus, the Forum has developed a 'network model' for TA (see Chapter 2) in which the plural landscape of many small institutions engaged in STI policy are drawn together around the formulation of 
policy recommendations for how to take into account broader impact dimensions of policy. Establishing the legitimacy of this solution is an ongoing process in which a balance is to be found with the institutions that remain from the communist era.

In Bulgaria, the Applied Research and Communications Fund (ARC Fund) has established itself as the premier research organisation into issues related to science and innovation policy. It was founded in 1991, and it is among the first post-communities-independent nongovernmental organisation in Bulgaria, as well as one of the very few still actively in operation. Since its inception, its ambition has been to support the development of the knowledge economy in Bulgaria and in Europe by introducing new policy concepts and innovative policymaking tools (such as foresight) by promoting policy consensus among actors in government, industry and civil society and by helping build the capacity of various professional groups. PACITA-project objectives were highly in line with these ambitions, and being a partner in PACITA further enabled ARC Fund to extend its methodological capacity by focusing more closely on the interlinkages among policy, science and technology, especially by stimulating civil society input through various participatory engagement methods. Although the concept and significance of technology assessment have gained in popularity, technology assessment as such is still not widely recognisable among stakeholders. Particularly in parliament, assessments of specific technologies have been performed with regard to social impacts. However, the scope and depth of this analysis were relatively narrowly defined and confined to a specific political agenda.

There still exists the need to define properly the best 'client' for technology assessments as parliament alone is often only the last among a range of policy actors who promote a specific policy development. This is in large part due to the structure of the legislative decision-making system, which facilitates much of the expert-based work to be done within ministries and other government agencies before it is submitted as a proposal to parliament and then debated and enacted within a relative short time frame. This presents ARC Fund with the opportunity (and challenge) to interact with a number of policy actors and to perform a number of functions, functions including expert identification and networking, quality assurance, (science) communication and policy uptake promotion, in addition to organisational and analytical tasks. 


\section{Possible new approaches to the adoption of TA}

A short opinion poll was taken at the end of the PACITA project among the countries, and these have been classified according to their selfevaluation of the institutional positioning in the STI policy advice. The opinion poll was based on four categories, defined as follows:

- Content marketer shall give politicians their desired 'shortcut', but the content marketer institution shall make it as methodologically correct and objective as possible within the limits of available financial and human resources.

- Eyes opener shall give politicians a glimpse what is going on at EU level or in other European countries and raise awareness on important issues. TA can be understood as a broad set of practices aimed at informing, shaping and prioritizing technology policies and innovation strategies, by deliberately appraising in advance their wider social, environmental and economic implications.

- Lobby organization shall aim at building up big coalitions and putting issues on political agendas, not at defending particular interests. Networking shall be used intensively to make personal relationships with policy makers and to form some general positive public opinion on knowledge-based policy making. If the resources allow, policy evaluations can be performed - showing shortcomings of current policies and providing general recommendations for action.

- Knowledge sharer shall concentrate on cross-border European exchange. There will always be a constant need for various examples of how one or another issue is solved in other countries. If Germany, Austria, The Netherlands or some other TA country can afford large-scale research on the impact of technologies developed in their countries on society in general - in the case of Eastern European countries and their budgetary constraints and undeveloped R\&D systems - then adapting already existing EU knowledge into the local context might be a more feasible solution. That's why cross-European cooperation of TA-like institutions is so important.

Representatives were asked to prioritize what is the likelihood that their institution would take over a particular function in the near future. The results are presented in Table 3.1 below. 
TABLE 3.1 Likelihood of institution taking over a particular function

\begin{tabular}{lcccc}
\hline Function/Country & Hungary & Czech Republic & Lithuania & Bulgaria \\
\hline TA as a 'content marketer' & 4 & 1 & 1 & 3 \\
TA as an 'eyes opener' & 2 & 4 & 4 & 1 \\
TA as an 'lobby organization' & 1 & 2 & 2 & horizontal \\
TA as a 'knowledge sharer' & 3 & 3 & 3 & 2 \\
\hline
\end{tabular}

By way of concluding this inside look, it is clear that adopting a TA role does not equate to taking a step up an evolutionary ladder. Rather, the tradition of parliamentary TA provides ideas and practices, which each organization cherry-picks from in ways that suit their organizational style and institutional role. From the point of view of these organizations, the ambition to expand TA across Europe thus provides a welcome source of new inspiration for already ongoing processes of institutional development and refinement in the STI field.

(c) (i) Except where otherwise noted, this work is licensed under a Creative Commons Attribution 4.0 Unported License. To view a copy of this license, visit https://creativecommons.org/version4 